\title{
Inhibition of histamine receptor H3R suppresses prostate cancer growth, invasion and increases apoptosis via the AR pathway
}

\author{
JUN CHEN and XIAO-YONG HU
}

\begin{abstract}
Department of Urology, Shanghai Jiao Tong University Affiliated Sixth People's Hospital, Shanghai 200233, P.R. China
\end{abstract}
Received November 26, 2017; Accepted July 17, 2018

DOI: $10.3892 / \mathrm{ol} .2018 .9310$

\begin{abstract}
Histamineh3 receptor(H3R) is expressed in numerous types of tumor and is associated with tumor cell proliferation, migration and invasion. However, whether H3R is expressed in prostate cancer remains unknown. Therefore, the expression and function of $\mathrm{H} 3 \mathrm{R}$ in prostate cancer was investigated. Immunohistochemistry, reverse transcription-quantitative polymerase chain reaction and western blotting all indicated overexpression of H3R in prostate cancer. Cell counting kit-8 (CCK-8), migration and invasion assays demonstrated that overexpressed H3R is associated with cell proliferation, migration and invasion. Inhibition of H3R induced cell apoptosis, however, androgen receptor protein expression was decreased. Overall, the results suggest that H3R is overexpressed in prostate cancer and associated with cell proliferation, migration and invasion. These results may broaden our understanding of the underlying pathological mechanisms of prostate cancer and aid the discovery of novel treatments for prostate cancer. These findings suggest that inhibition of H3R may have favorable application prospects in the treatment of prostate cancer.
\end{abstract}

\section{Introduction}

In United States, prostate cancer is a major threat to the health of men (1), and, in China, the incidence of prostate cancer has increased (2). Previous studies have revealed that androgen serves an important role in the development of prostate cancer. In the early stage of prostate cancer, androgen is essential for the proliferation of the cancer cells, and is also crucial in the recurrent or metastatic stage $(3,4)$. Androgen deprivation therapy (ADT) successfully inhibits this process in patients $(5,6)$. Methods of ADT include castration and anti-androgen therapy, however, ADT presents numerous disadvantages, including surgical trauma and complication, and

Correspondence to: Dr Xiao-Yong Hu, Department of Urology, Shanghai Jiao Tong University Affiliated Sixth People's Hospital, 600 Yishan Road, Xuhui, Shanghai 200233, P.R. China

E-mail: xiaoyonghu@126.com

Key words: histamine receptor H3R, prostate cancer, androgen receptor, $\mathrm{LNCaP}$ heavy economic burden, particularly in China (7). Therefore, it is important to identify novel and more economical therapies for prostate cancer, and inhibition of the histamine receptor has been suggested to have potential $(8,9)$.

Histamine receptor includes 4 subtypes, namely, histamine h1 receptor (H1R), histamine h2 (H2R), h3 (H3R) and h4 (H4R). The histamine receptor is activated by histamine and restrained by histamine receptor antagonists. In 1979, Armitage (8) reported that a histamine receptor antagonist (cimetidine) had an antitumor effect, however, the mechanism was uncharacterized. Since, the majority of scholars believe that histamine and histamine receptors serve a role in the promotion in tumor growth and invasion, and histamine receptor antagonists, the contrary (10-13). In in vivo trials, histamine receptor antagonists have been reported to increase the release of prolactin in male animals (14). However, the proposed mechanisms of the role of histamine in regulation of the release of androgen are various, and Wang et al (9) suggest that histamine functions without the histamine receptor. H3R has been demonstrated to be overexpressed in multiple types of cancer $(12,13)$, and the present study demonstrated that histamine and $\mathrm{H} 3 \mathrm{R}$ were overexpressed in prostate cancer cells compared with normal prostatic epithelial cells. Therefore, we hypothesized that H3R has a potential role in the development of prostate cancer and aimed to explore the underlying mechanism.

The present study can be divided into four parts: i) Exploration of $\mathrm{H} 3 \mathrm{R}$ expression in prostate cancer cell lines by reverse transcription-quantitative polymerase chain reaction (RT-qPCR), western blotting and immunohistochemistry of a prostate cancer tissue array; ii) inhibition of the expression of H3R in prostate cancer cell lines by antagonists or small-interfering RNA (siRNA) to determine the role of H3R in cancer cells; iii) investigate downstream signaling pathways following si-H3R transfection, and iv) verify the effect of si-H3R on a nude mouse xenograft model. Evidence indicates that H3R is involved in multiple tumor processes, and the present study may broaden our understanding of the underlying pathological mechanisms, as well as aid in the discovery of novel treatment targets.

\section{Materials and methods}

Cell lines and prostate cancer tissue chip. The prostate cancer cell lines, PC-3, LNCaP and 22RV1, were purchased from the 
Institute of Biochemistry and Cell Biology (Chinese Academy of Sciences, Shanghai, China). C4-2 cells were a gift from Dr Guo-wen Lin (Fudan University Shanghai Cancer Center, Shanghai, China). The normal human prostate epithelial cell line, RWPE-1, was purchased from the American Type Culture Collection (Manassas, VA, USA). PC-3, LNCaP, C4-2 and 22RV1 cells were cultured in RPMI-1640 medium supplemented with $10 \%$ fetal bovine serum (FBS) and $1 \%$ penicillin-streptomycin (all from Gibco; Thermo Fisher Scientific, Inc., Waltham, MA, USA). RWPE-1 cells were cultured in keratinocyte serum-free medium (K-SFM; cat. no. 17005-042; Invitrogen; Thermo Fisher Scientific, Inc.) supplemented with $0.05 \mathrm{mg} / \mathrm{ml}$ bovine pituitary extract (BPE), $5 \mathrm{ng} / \mathrm{ml}$ epidermal growth factor (EGF; both from K-SFM medium kit; cat. no. 17005-042; Invitrogen; Thermo Fisher Scientific, Inc), according to the manufacturer's protocols, and $1 \%$ of penicillin-streptomycin (Gibco). All media was changed every 2-3 days, and the cells were passaged at $80-90 \%$ confluency. The prostate cancer tissue array was purchased from Biomax USA (US Biomax, Inc., Derwood, MD, USA).

Cytotoxicity assays. Cell Counting kit-8 (CCK-8) assays were performed by plating $5 \times 10^{3} \mathrm{LNCaP}$ cells per well in a 96 well plate (Thermo Fisher Scientific, Inc.). The following day, cells were treated with $0,10,100 \mathrm{nM}$, and 1, 5, $10 \mu \mathrm{M}$ of R-(a)-methylhistamine (RAMH; cat. no. B5010; Apexbio, Houston, TX, USA) and $0,10,100 \mathrm{nM}$ and $1,5,10 \mu \mathrm{M}$ ciproxifan (CPX; cat. no. S2813; Selleck, Houston, TX, USA). The cells were exposed to the drugs for 1-2 days prior to the addition of CCK-8 reagent (cat. no. 40203ES60; Yeasen; Shanghai Yi San Biotechnology Co., Ltd., Shanghai, China) for $2 \mathrm{~h}$, according to the manufacturer's protocol, and the absorbance of each well was detected using a microplate reader (Thermo Fisher Scientific, Inc) at a wavelength of $450 \mathrm{~nm}$.

H3R-knockdown studies. Transient knockdown was performed using siRNA targeting H3R (Ruibobio, Guangzhou, Guangdong, China) and non-targeting siRNA as a negative control. The siRNA sequences were as follows: si-H3R, 5'-GCTATGCCGAGTTCTTCTACA-3', and negative control, 5'-TTCTCCGAACGTGTCACGT-3'. In brief, LNCaP cells $\left(5 \times 10^{4}\right.$ in 24 -well plate) were transfected with siRNA (both $20 \mathrm{pmol}$ in $500 \mu \mathrm{l} /$ well) with Lipofectamine $2000(1 \mu \mathrm{l}$ in $500 \mu \mathrm{l} /$ well, Invitrogen; Thermo Fisher Scientific, Inc.), according to the manufacturer's protocol. The LNCaP cells used for transplant were transfected with si-H3R-packaged lentivirus $(\mathrm{MOI}=20)$ and selected using puromycin $(2 \mu \mathrm{g} / \mathrm{ml}$ for 10 days) (Sigma-Aldrich; Merck KGaA, Darmstadt, Germany) according to the manufacturer's protocol.

Migration and invasion assays. The upper chamber of a 24-well plate (Corning Incorporated, Corning, NY, USA) was pre-coated with $50 \mu$ l Matrigel (BD Biosciences, Franklin Lake, NJ, USA) for the invasion assay. The following steps were the same for the two assays. A total of $1 \times 10^{5} \mathrm{LNCaP}$ cells were suspended in $200 \mu \mathrm{l}$ serum-free RPMI-1640 medium and seeded into the upper chamber of a 24-well plate. A total of $900 \mu 1$ RPMI-1640 medium supplemented with $20 \%$ FBS was added to lower chamber of each well. After $24 \mathrm{~h}$, the cells were fixed using
4\% paraformaldehyde for $30 \mathrm{~min}$ at room temperature (Mairel; Shanghai Miner Chemical Technology Co., Ltd., Shanghai, China) and stained with $0.1 \%$ crystal violet (Mairel; Shanghai Miner Chemical Technology Co., Ltd) for $30 \mathrm{~min}$ at room temperature. Cells on the upper surface of the Transwell insert were removed with a cotton swab and cells on the lower surface were counted under a light microscope (Olympus Corporation, Tokyo, Japan) in three fields of view (magnification, x100).

Apoptosis assay. Measurement of in vitro apoptosis was performed by Annexin V-FITC/propidium iodide (PI) staining Apoptosis Detection kit ( Yeasen; Shanghai Yi San Biotechnology Co., Ltd.), according to the manufacturer's instructions, using a flow cytometer (Beckman Coulter, Inc., Brea, CA, USA).

Reverse transcription-quantitative polymerase chain reaction. Total RNA was extracted using a Takara RNeasy Mini kit (cat. no. 9767; Takara Bio, Inc., Otsu, Japan), according to manufacturer's instructions. RNA was transcribed into cDNA using a PrimeScript RT reagent kit (cat. no. RR036A; Takara Bio, Inc.). A Takara qPCR kit (cat. no. RR420Q; Takara Bio, Inc.) was used to assess H3R gene expression using an ABI 7500 real-time system (Applied Biosystems; Thermo Fisher Scientific, Inc.). The thermocycling conditions were as follows: $30 \mathrm{sec}$ at $95^{\circ} \mathrm{C}, 5 \mathrm{sec}$ at $95^{\circ} \mathrm{C}, 34 \mathrm{sec}$ at $60^{\circ} \mathrm{C}$ and 40 cycles of $15 \mathrm{sec}$ at $95^{\circ} \mathrm{C}, 60 \mathrm{sec}$ at $60^{\circ} \mathrm{C}$, and $15 \mathrm{sec}$ at $95^{\circ} \mathrm{C}$. Relative gene expression was normalized to that of GAPDH. Gene expression was quantified using the $2^{-\Delta \Delta \mathrm{Cq}}$ method (15). The primer sequences used were as follows: H3R forward, 5'-GCC ACTGCTATGCCGAGTT-3' and reverse, 5'-TGCGCCTCT GGATGTTCAG-3'; GAPDH forward, 5'-TTTACCTTCCAG CAGCCCTA-3' and reverse, 5'-GACAGAGTCCCAGATGAG CA-3'.

Western blotting. Total protein was extracted with radioimmunoprecipitation assay (RIPA) buffer (Beyotime Institute of Biotechnology, Haimen, China) adding $1 \mathrm{mM}$ protease inhibitor cocktail (Beyotime Institute of Biotechnology) at $4{ }^{\circ} \mathrm{C}$ between $30 \mathrm{~min}$ and $1 \mathrm{~h}$ then concentrate under 12,000 rpm at $4^{\circ} \mathrm{C}$ for $15 \mathrm{~min}$. Total protein concentration was determined using a bicinchoninic acid (BCA) kit (cat. no. P0010; Beyotime Institute of Biotechnology, Haimen, China). The protein (30 $\mu \mathrm{g}$ per lane) samples were resolved by $10 \%$ SDS-PAGE and transferred to polyvinylidene fluoride (PVDF) membranes. The membranes were then blocked with $5 \%$ non-fat milk for $1 \mathrm{~h}$ at room temperature. The membranes were probed with the following primary antibodies overnight at $4^{\circ} \mathrm{C}$ : H3R (dilution, 1:5,000; cat. no. ab124732; Abcam, Cambridge, UK), BAX (BCL-2 associated $\mathrm{X}$, apoptosis regulator; dilution, 1:1,000; cat. no. D2E11), BCL2 (dilution, 1:1,000; cat. no. D17C4; Cell Signaling Technology, Inc., Danvers, MA, USA), AR (dilution, 1:500; cat. no. sc-7305; Santa Cruz Biotechnology, Dallas, TX, USA), GAPDH (dilution, 1:5,000; cat. no. 70-Mab5465-040; Multi Sciences; Hangzhou Lianke Biotechnology Co., Ltd., Hangzhou, China). The membranes were then incubated with the appropriate horseradish peroxidase-conjugated secondary antibody: Anti-rabbit IgG (dilution, 1:1,000; cat. no. 7074) or anti-mouse IgG (dilution, 1:1,000; cat. no. 7076; both Cell Signaling Technology, Inc.) at room temperature 
Table I. The expression of H3R protein in different prostate tissues in the array.

\begin{tabular}{lrrrr}
\hline & \multicolumn{2}{c}{$\begin{array}{c}\text { H3R immu- } \\
\text { noreactivity }\end{array}$} & \\
\cline { 2 - 3 } Prostate pathology & - & + & ++ & P-value \\
\hline Prostate cancer $(\mathrm{n}=40)$ & 0 & 17 & 23 & $\mathrm{P}<0.01$ \\
Normal prostate tissue $(\mathrm{n}=8)$ & 5 & 3 & 0 & \\
\hline
\end{tabular}

H3R, histamine 3 receptor.

Table II. The association between H3R expression and gleason score in prostate cancer.

\begin{tabular}{lrrrr}
\hline $\begin{array}{l}\text { Gleason score } \\
\text { in prostate } \\
\text { cancer }(\mathrm{n}=36)\end{array}$ & \multicolumn{2}{c}{$\begin{array}{l}\text { H3R immu- } \\
\text { noreactivity }\end{array}$} & & $\begin{array}{c}\text { Difference } \\
\text { in H3R } \\
\text { expression }\end{array}$ \\
\cline { 2 - 3 } & + & ++ & \\
\hline $6-7$ & 13 & 1 & $\mathrm{P}<0.01$ \\
$8-10$ & 4 & 18 & \\
\hline
\end{tabular}

H3R, histamine 3 receptor.

for $1 \mathrm{~h}$. The two secondary antibodies were diluted at 1:1,000 and were purchased from Cell Signaling Technology, Inc. The blots were visualized using ECL-Plus reagent (cat. no. WBKLS0010; Merck Millipore; Merck KGaA, Darmstadt, Germany). Images were acquired with the ImageQuant LAS 4000mini (GE Healthcare Bio-Sciences, Pittsburgh, PA, USA) and analyzed with ImageJ 2.1.4.7 software (National Institutes of Health, Bethesda, MD, USA). The results were expressed as the target protein/GAPDH ratio and subsequently normalized to the values measured in the control groups.

Immunohistochemistry. Prior to immunohistochemistry, the tissue array and the xenograft tumor slides were placed in a washing solution of $3 \%$ hydrogen peroxide $\left(\mathrm{H}_{2} \mathrm{O}_{2}\right)$ and $60 \%$ methanol phosphate buffered saline (PBS) (PH 7.4) for $30 \mathrm{~min}$ and subsequently treated with $0.01 \mathrm{~mol} / \mathrm{l}$ sodium citrate buffer for $95^{\circ} \mathrm{C}$ in a microwave oven for $15 \mathrm{~min}$ for antigen retrieval. The tissue array and the xenograft tumor slides were subsequently blocked in 5\% normal goat serum and 5\% bovine serum albumin (Yeasen; Shanghai Yi San Biotechnology Co., Ltd) in PBS for $15 \mathrm{~min}$ at $37^{\circ} \mathrm{C}$. Prior to each step, the tissue array and the xenograft tumor slides were rinsed three times in PBS buffer. The array was incubated with a H3R primary antibody (dilution, 1:100; cat. no. ab124732; Abcam) and the xenograft tumor slides with Ki67 (dilution, 1:400; cat. no. 9449; Cell Signaling Technology, Inc.) and TUNEL (dilution, 1:500; cat. no. ab206386; Abcam) each for $12 \mathrm{~h}$ at $4^{\circ} \mathrm{C}$. Subsequent to rinsing with PBS, the sections were incubated with a secondary horseradish peroxidase-conjugated antibody anti-rabbit IgG (dilution, 1:200; cat. no. 7074; Cell Signaling Technology, Inc) for $1 \mathrm{~h}$ at room temperature. $0.05 \%$ diaminobenzidine (Beyotime Institute of Biotechnology) exposure was performed using chromogen at room temperature about $5 \mathrm{~min}$. Finally, the array and the xenograft tumor slide were counterstained with $0.025 \%$ hematoxylin (Beyotime Institute of Biotechnology) at room temperature for $\sim 30 \mathrm{sec}$.

Xenograft tumor studies. All animal procedures were performed according to the National Animal Experimentation guidelines and were approved by the ethics committee of the Shanghai Jiao Tong University (Shanghai, China). Male 4-8 week-old nude mice weighing $20-25 \mathrm{~g}$ were used in the following experiments. A total of 8 mice were divided equally and randomly into 2 groups. All mice were bred in aseptic conditions at a constant humidity $(\sim 40-70 \%)$ between 20 and $26^{\circ} \mathrm{C}$ with standard $12 \mathrm{~h}$ light-dark cycles and free access to food and water. For tumor xenograft studies, $5 \times 10^{6} \mathrm{LNCaP}$ cells were suspended in $0.1 \mathrm{ml}$ serum-free media containing 50\% Matrigel, and injected subcutaneously into the oxter of the mice, which were then observed every three days. Once the tumors reached $1 \mathrm{~cm}$ in diameter, the mice were sacrificed and the tumor volumes were calculated using the following formula: $0.5 \mathrm{x}$ length $(\mathrm{mm}) \mathrm{x}$ width ${ }^{2}\left(\mathrm{~mm}^{2}\right)$. The tumors were fixed in $10 \%$ formalin at $4^{\circ} \mathrm{C}$ between 24 and $48 \mathrm{~h}$, and embedded in paraffin for incubation with the aforementioned primary antibodies, Ki67 and TUNEL.

Statistical analysis. SPSS 22.0 (IBMCorp., Armonk, NY,USA) and Graph Pad Prism (version 5; Graph Pad Software, Inc., La Jolla, CA, USA) were used to analyze the data and all values are expressed as mean \pm standard deviation. One-way analysis of variance followed by the LSD or Dunnett's T3 post-hoc tests was used for multiple comparisons. The Mann-Whitney U test was used to compare differences between H3R expression in prostate cancer and normal tissues. Fisher's exact test was used to assess differences in H3R expression in prostate cancer tissues with different Gleason scores. $\mathrm{P}<0.05$ was considered to indicate a statistically significant differences.

\section{Results}

$H 3 R$ is overexpressed in prostate cancer tissues and cells. Previous studies have demonstrated that H3R is overexpressed in various types of cancer, however, there are limited reports of the expression of H3R in prostate cancer. In the present study, the tissue array demonstrated positive immunoreactivity of H3R in the majority of cancer tissues but negative immunoreactivity in normal tissues, and the two tissue groups were significantly different $(\mathrm{P}<0.01)$ (Fig. 1A-F; Table I). It was demonstrated that the expression of H3R was positively associated with Gleason score $(\mathrm{P}<0.01$; Table II). RT-qPCR analysis demonstrated that $\mathrm{H} 3 \mathrm{R}$ mRNA is overexpressed in prostate cancer cells. In LNCaP, 22rv1 and C4-2 cells, the expression of H3R was $>20$-fold than that of normal prostatic epithelial cells $(\mathrm{P}<0.01)$ (Fig. 1G). Western blotting demonstrated the same result at the protein level. All cancer cell lines exhibited higher expression of H3R than normal prostatic epithelial cells $(\mathrm{P}<0.05)$. LNCaP cells exhibited the highest expression of H3R (Fig. 1H-I), and were therefore, selected for further experimentation. Thus, the tissue array, RT-qPCR analysis and western blotting all suggested that expression of H3R in prostate cancer is significantly higher than that in normal prostatic epithelial tissues. 

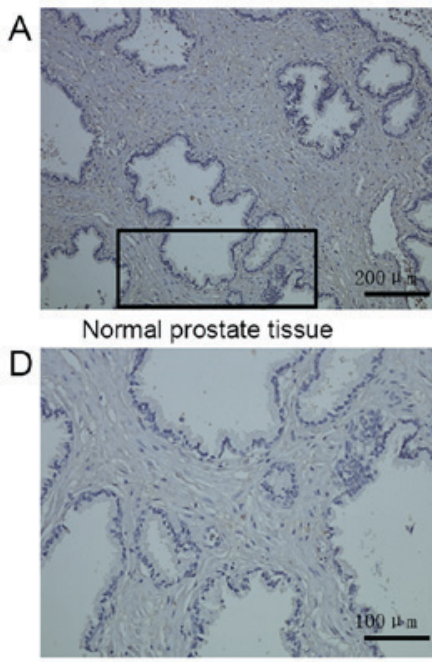

Normal prostate tissue

G

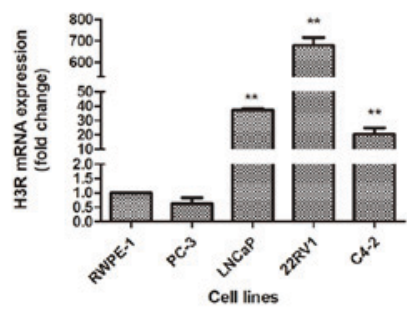

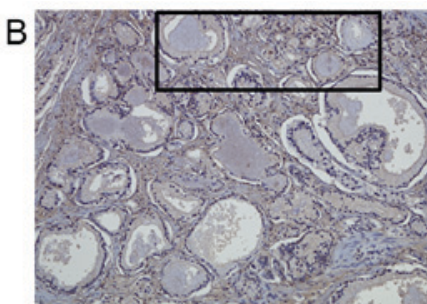

Prostate cancer (Gleason 6-7)

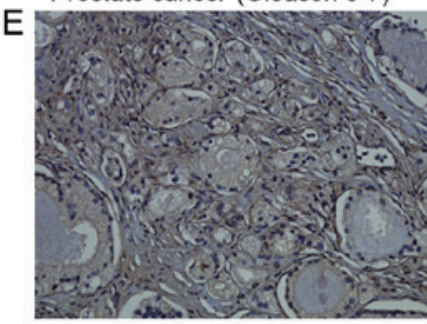

Prostate cancer (Gleason 6-7)

$\mathrm{H}$

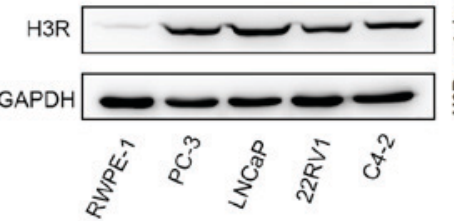

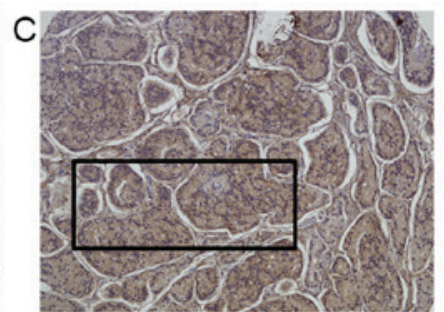

Prostate cancer (Gleason 8-10)

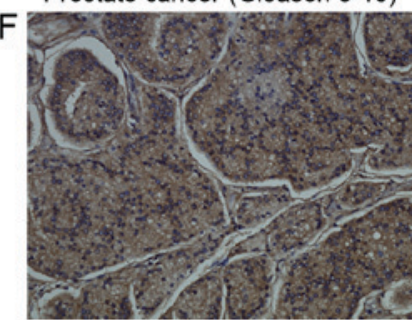

Prostate cancer (Gleason 8-10)

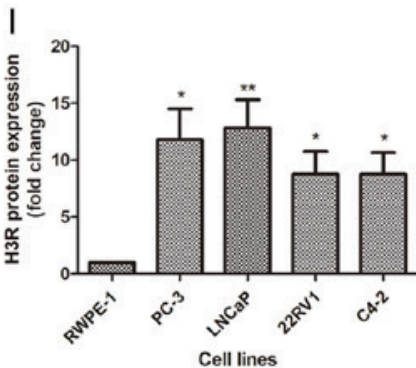

Figure 1. Overexpression of H3R in prostate cancer. Representative immunohistochemical images of H3R protein expression in the prostate cancer tissue array. (A) Normal tissue, (B) prostate cancer tissue (Gleason stage 6-7), (C) prostate cancer tissue (Gleason stage 8-10), magnification, x100. Enlarged images of the outlined panels of (D) Normal tissue, (E) prostate cancer tissue (Gleason 6-7), (F) prostate cancer tissue (Gleason stage 8-10), magnification, x200. H3R expression measured by $(\mathrm{G})$ reverse transcription-quantitative polymerase chain reaction, and (H) western blotting. (I) Quantification of western blotting results. "P<0.05 vs. RWPE-1; ${ }^{* *} \mathrm{P}<0.01$ vs. RWPE-1. H3R, histamine 3 receptor.

$H 3 R$ regulates the proliferation of LNCaP cells. In order to reveal the role of $\mathrm{H} 3 \mathrm{R}$ in $\mathrm{LNCaP}$ cells, a specific H3R agonist $(\mathrm{RAMH})$ and antagonist (CPX) were used. Pretreatment with RAMH promoted the proliferation of LNCaP cells in a dose-dependent manner. In contrast, pretreatment with CPX suppressed proliferation of LNCaP cells in a dose-dependent manner (Fig. 2A-C). In previous studies by our group, it was reported that histamine receptor antagonists may function without a histamine receptor. Therefore, an siRNA was designed to target H3R. Following si-H3R treatment of LNCaP cells (Fig. 2D-F) their proliferation declined by $20 \%$ more than that of si-NC LNCaP cells in one day $(\mathrm{P}<0.01)$ (Fig. 2G).

Inhibition of $H 3 R$ expression suppresses metastatic behaviour of LNCAP cells. Knockdown of H3R expression decreased the migration $(\mathrm{P}<0.01)($ Fig. 3A-C) and invasion $(\mathrm{P}<0.01)$ (Fig. 3D-F) of the LNCaP cells compared with si-NC-transfected cells.

Inhibition of H3R expression induces apoptosis of LNCAP cells. Flow cytometric analysis of apoptosis revealed that knockdown of H3R lead to increased apoptosis than control si-NC cells $(\mathrm{P}<0.01)$ (Fig. 4E-F and $\mathrm{H})$. Treatment with $10 \mu \mathrm{M}$ H3R agonist decreased apoptosis whereas treatment with $10 \mu \mathrm{M} \mathrm{H} 3 \mathrm{R}$ antagonist increased apoptosis. When used in conjunction, the effects of both drugs were weakened (Fig. 4A-D and $\mathrm{H}$ ). These results indicate that knockdown of H3R lead to apoptosis of LNCaP cells.

BCL-2 signaling pathways have been reported to serve a key role in prostate cancer-cell apoptosis (16). The BCL-2 family contains BCL-2, BAX, BAK and BCL-XL. It was demonstrated that knockdown of H3R significantly decreased the level of BCL2 (anti-apoptosis gene) expression $(\mathrm{P}<0.01)$, and increased the level of BAX (apoptosis-associated gene) expression $(\mathrm{P}<0.05)$. It also confirmed in specific H3R agonist and antagonist assay (Fig. 4).

$H 3 R$ activates proliferation through androgen receptor $(A R)$ pathways. Numerous pathways have been demonstrated to be involved in the development and progression of prostate cancer, including AR, PI3K/AKT, MYC and PTEN (17-20). AR has been demonstrated to accelerate the proliferation of prostate cancer cells, therefore, in the present study, the expression of AR was investigated following H3R-knockdown. Western blotting revealed that the expression of AR was significantly reduced following knockdown of H3R compared with si-NC-transfected cells $(\mathrm{P}<0.05)$. This indicates that the expression of AR is associated with the expression of $\mathrm{H} 3 \mathrm{R}$ (Fig. 4G and I). The H3R agonist and antagonist were used in parallel and CPX reduced the expression of AR while RAMH increased the expression of AR (Fig. 4).

H3R knockdown suppresses prostate cancer growth in vivo. To reveal the effect of H3R-knockdown in vivo, a xenograft 

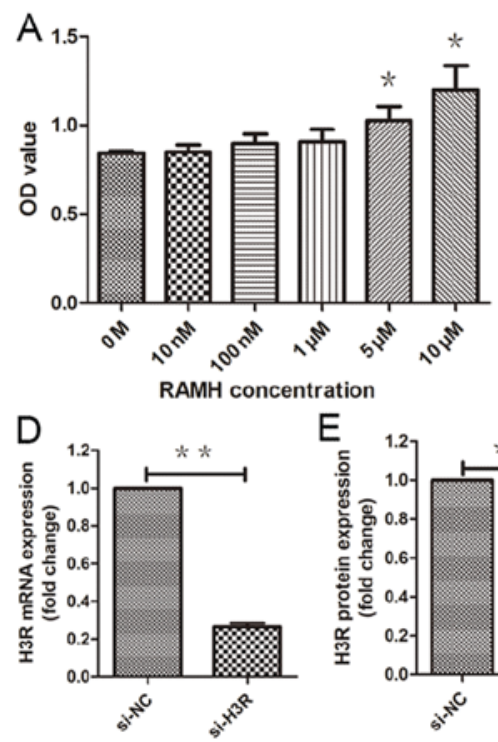

$B$

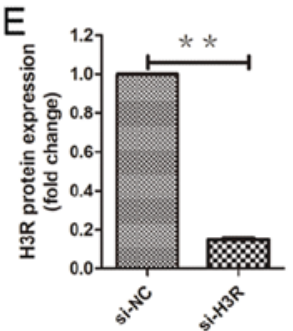

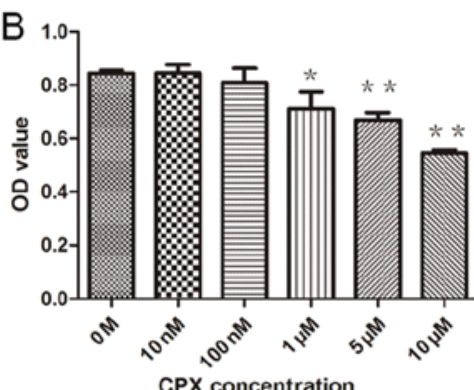

$\mathrm{F}$

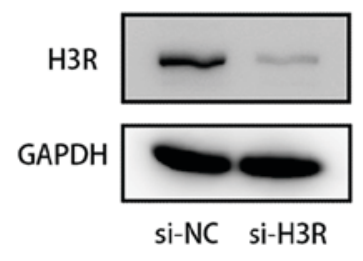

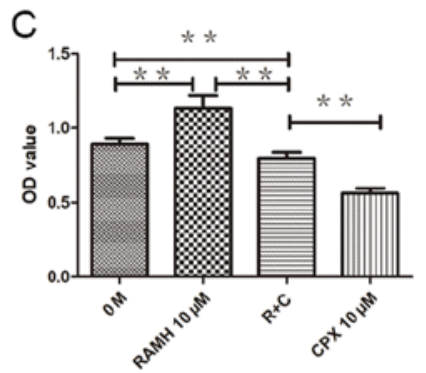

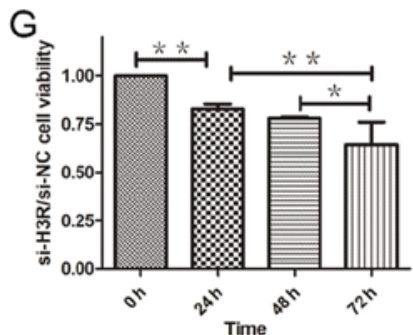

Figure 2. H3R-knockdown or antagonist treatment decreased the proliferation of LNCaP cells. The effects of (A) RAMH, (B) CPX, and (C) combination treatment on the proliferation of LNCaP cells. Si-H3R significantly decreased (D) H3R mRNA expression and (E) protein expression. (F) Western blot indicating reduced H3R protein expression. (G) Si-H3R also reduced proliferation of LNCaP cells. "P $<0.05$ and ${ }^{* *} \mathrm{P}<0.01$. H3R, histamine 3 receptor; RAMH, R-(a)-methylhistamine; CPX, ciproxifan; si, small interfering RNA; NC, negative control; OD, optical density.
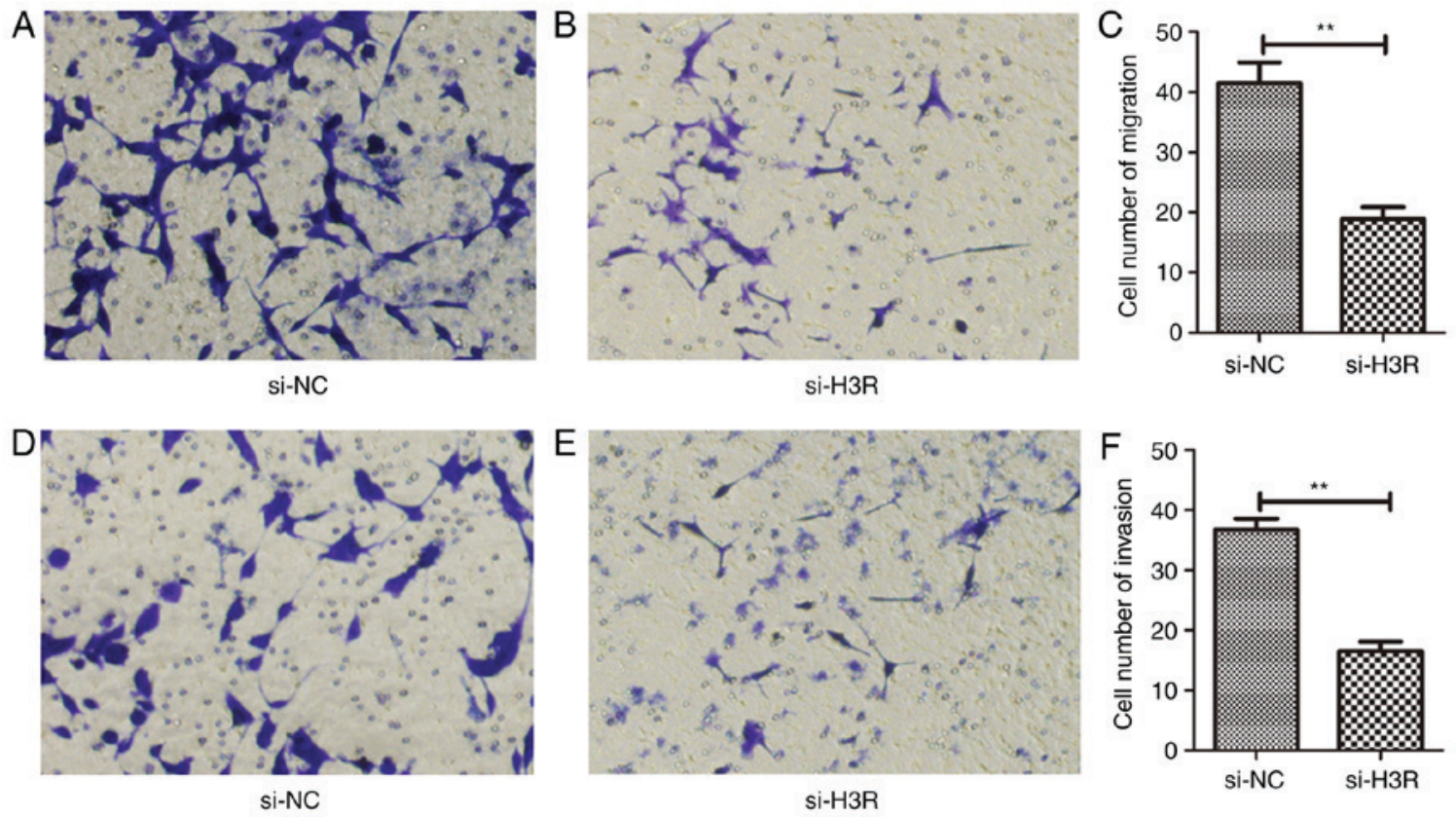

Figure 3. H3R-knockdown decreased the metastatic and invasive abilities of LNCaP cells. Downregulation of H3R by si-RNA inhibited cell migration. (A) Migration of LNCaP cells transfected with si-NC, (B) migration of LNCaP cells transfected with si-H3R, (C) quantification of migratory cells, (D) invasion of $\mathrm{LNCaP}$ cells transfected with si-NC, (E) invasion of $\mathrm{LNCaP}$ cells transfected with si-H3R, and (F) quantification of invasive cells. ${ }^{* *} \mathrm{P}<0.01$. H3R, histamine 3 receptor; si, small interfering; $\mathrm{NC}$, negative control.

model was established in nude mouse using si-H3R-transfected LNCaP cells (LNCaP siH3R) and negative control (NC) transfected LNCaP cells (LNCaP si-NC). The length and width of the tumor were measured twice a week. After 8 weeks, the tumors in the LNCaP si-NC group grew to $\sim 1 \mathrm{~cm}$ while tumors in the LNCaP si-H3R group only grew to $\sim 0.5 \mathrm{~cm}$, and the difference was significantly different $(\mathrm{P}<0.05)$ (Fig. 5A-E). Furthermore, immunohistochemistry revealed that the expression of Ki67 (proliferation marker) was significantly in the LNCaP si-H3R group than the LNCaP si-NC group $(\mathrm{P}<0.01)$ (Fig. 5F-H). The expression of TUNEL (apoptosis marker) was significantly increased in the LNCaP si-H3R group compared with the LNCaP si-NC group $(\mathrm{P}<0.01)$ (Fig. 5I-K).

\section{Discussion}

The expression of histamine receptor in prostate cancer has been insufficiently studied. It has been demonstrated that histamine receptor serves a key role in the nervous system (21). Lin et al revealed that inhibition of the expression of H3R could 


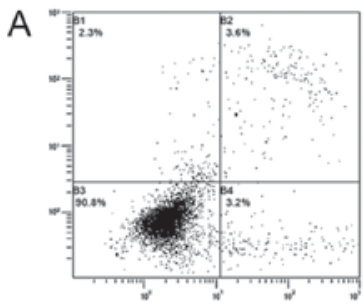

PBS

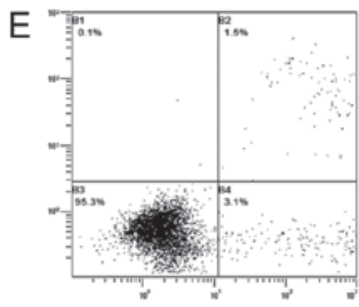

si-NC

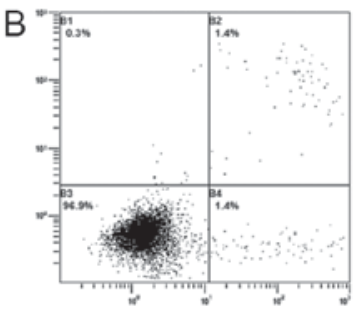

$\mathrm{RAMH}$

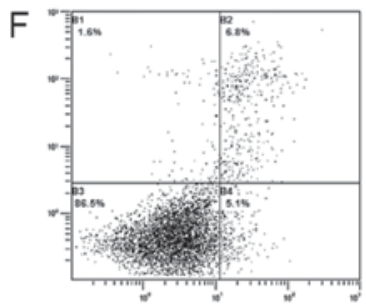

$\mathrm{si}-\mathrm{H} 3 \mathrm{R}$

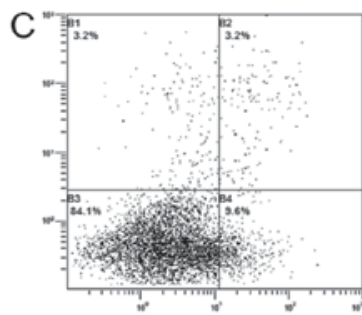

$\mathrm{RAMH}+\mathrm{CPX}$

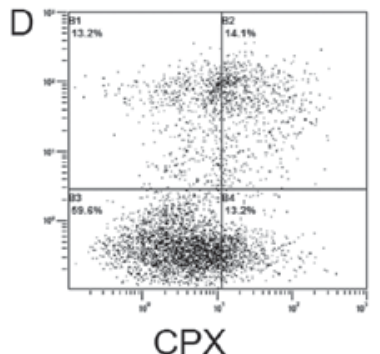

$\mathrm{CPX}$

G
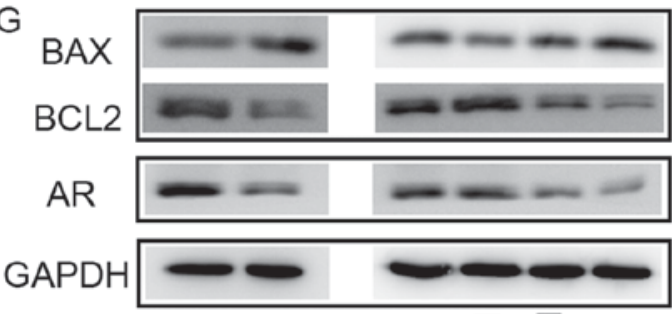

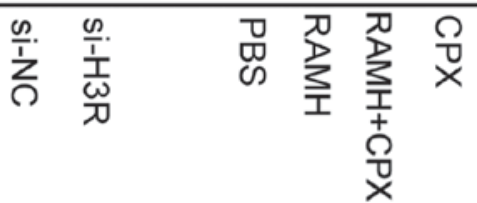
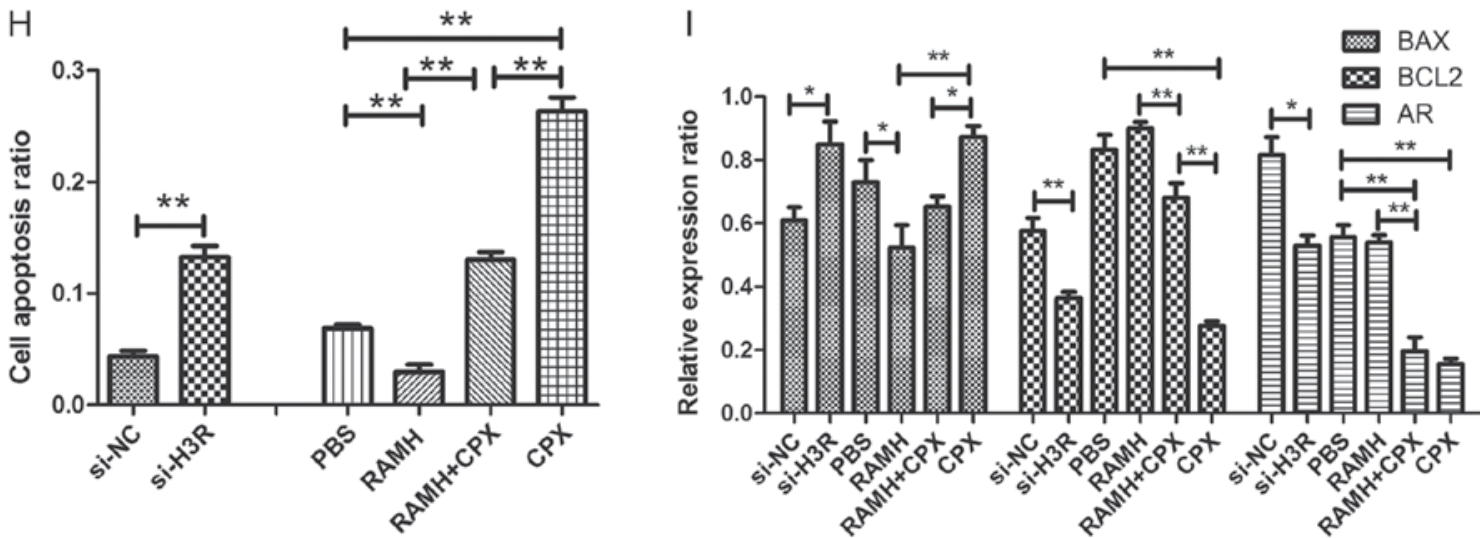

Figure 4. Inhibition of H3R function by siRNA or antagonist increased the apoptosis of LNCaP cells and their protein expression profile. The effects of (A) PBS control, (B) RAMH, (C) RAMH+CPX, (D) CPX, (E) si-NC and (F) si-H3R. (G) Western blotting analysis of BAX, BCL-2 and AR protein expression. (H) Apoptosis of LNCaP cells following treatment with siRNAs, RAMH and CPX. (I) Quantification of protein expression. ${ }^{*} \mathrm{P}<0.05$ and ${ }^{* *} \mathrm{P}<0.01$. $\mathrm{H} 3 \mathrm{R}$, histamine 3 receptor; si, small interfering; NC, negative control; RAMH, R-(a)-methylhistamine; CPX, ciproxifan; BAX, BCL-2 associated X, apoptosis regulator; AR, androgen receptor.

suppress the growth and invasion of glioblastoma tumor (13). Previous studies have demonstrated that histamine receptor may influence the secretion of sex hormones (22). Therefore, the present study aimed to elucidate the role of $\mathrm{H} 3 \mathrm{R}$ in prostate cancer.

Preliminarily, the expression of 4 histamine receptors (H1R-H4R) were investigated in prostate cancer (data are not shown). Among the 4 histamine receptors, the expression of H3R was the highest, and H3R-knockdown lead to the inhibition of the LNCaP cell proliferation, migration and invasion. si-H3R also induced the apoptosis of prostate cancer cells and inhibited the expression of androgen receptor.

Androgen is essential to maintain male sex characteristics, and has also been demonstrated to promote the occurrence of prostate cancer (23). It has been indicated that androgen requires androgen receptor to increase the growth of prostate cancer (24), but androgen has the ability to promote production of androgen receptor (25). Androgen receptor is overexpressed in prostate cancer can harbor mutations which result in spliceosomes (AR-Vs) (26), these mutations allow prostate cancer cells to grow in very low concentrations of androgen $(27,28)$. Therefore, targeting androgen and androgen receptor has been clinically researched in prostate cancer with good results $(29,30)$. In the present study, it was demonstrated that when H3R was inhibited, the expression of androgen receptor decreased. This indicates that the influence of $\mathrm{H} 3 \mathrm{R}$ on $\mathrm{LNCaP}$ cells may occur via androgen receptor.

The role of H3R in tumor-cell proliferation has been reported in various types of cancer (31-33), however, reports of $\mathrm{H} 3 \mathrm{R}$ expression in prostate cancer are limited. In the present study, it was demonstrated that $\mathrm{H} 3 \mathrm{R}$ is overexpressed in prostate cancer, that it can influence the proliferation, migration and invasion of prostate cancer cells, as well as the downstream androgen receptor. However, the mechanism by which $\mathrm{H} 3 \mathrm{R}$ regulates the expression of androgen 

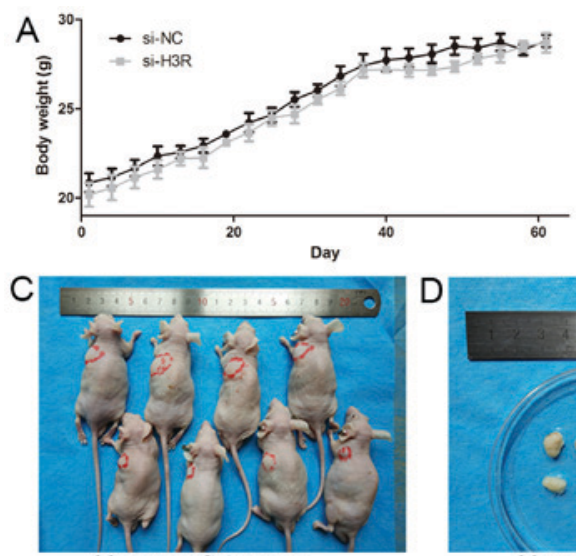

Xenograft tumors

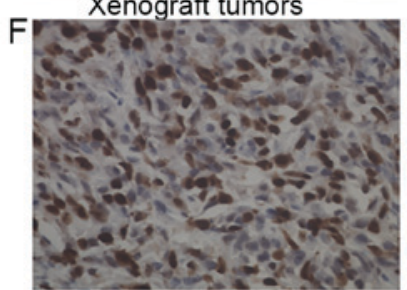

Ki67 in si-NC

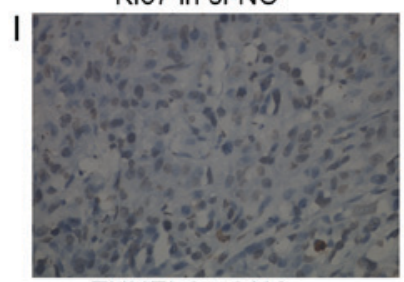

TUNEL in si-NC
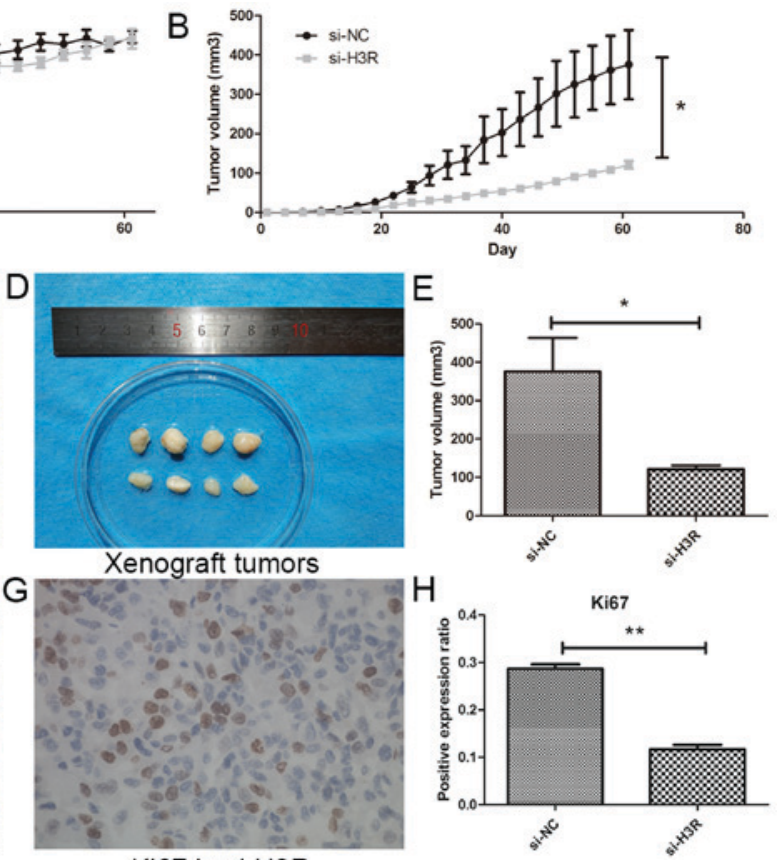

Ki67 in si-H3R

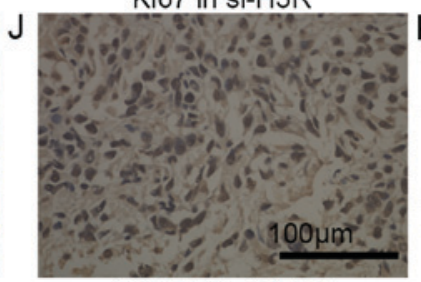

TUNEL in si-H3R

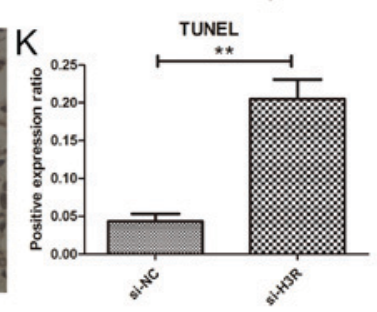

Figure 5. H3R-knockdown inhibits tumor growth in a xenografted model. (A) Body weights of mice treated with si-NC or si-H3R-transfected cells over time. (B) Tumor volume change between 0 and 60 days in mice treated with si-H3R-transfected cells compared with the control group. (C) Xenograft tumor on the mice and (D) the isolated tumor in the xenografted model. (E) Tumor volume change in mice treated with si-H3R-transfected cells compared with the control group. Representative images of immunohistochemical staining of Ki67, expression ratio of Ki67 is higher in (F) si-NC compared with (G) si-H3R (H) Quantification of Ki67 expression. Representative images of immunohistochemical staining of TUNEL, expression ratio of TUNEL is less in (I) si-NC compared with (J) si-H3R. (K) Quantification of TUNEL expression. Magnification, $\mathrm{x} 400$. "P<0.05 and ${ }^{* * *} \mathrm{P}<0.01$. H3R, histamine 3 receptor; si, small interfering; NC, negative control.

receptor remains undetermined. Whether $\mathrm{H} 3 \mathrm{R}$ has a similar role in castration-resistant prostate cancer or whether it functions in the switch of hormone-responsive prostate cancer to castration-resistant prostate cancer, also remains to be determined. The results of the present study broaden our understanding of the underlying pathological mechanisms and may aid in the discovery of novel treatment targets in prostate cancer. Future studies should consider the potential of combined treatment of H3R-inhibition treatment with other standard therapies, including chemotherapy or androgen deprivation therapy. The biological functions of $\mathrm{H} 3 \mathrm{R}$ determines provide a foundation for further investigation.

\section{Acknowledgements}

The authors thank Dr Guo-wen Lin (Fudan University Shanghai Cancer Center) for providing the C4-2 cell lines.

\section{Funding}

The present study was supported by the Med-Tech Crossdisciplinary Foundation of Shanghai Jiao Tong University (grant no. YG2012MS55).

\section{Availability of data and materials}

All data generated or analyzed during the present study are included in this published article.

\section{Ethics approval and consent to participate}

The present study was approved by Shanghai Jiao Tong University Ethics Committee. Written informed consent was obtained from all participants.

\section{Authors' contributions}

JC and XH contributed to all experiments.

\section{Patient consent for publication}

The authors declare that the patients have provided written informed consent for the publication.

\section{Competing interests}

The authors declare that they have no competing interests. 


\section{References}

1. Siegel RL, Miller KD and Jemal A: Cancer statistics, 2016. CA Cancer J Clin 66: 7-30, 2016.

2. Chen W, Zheng R, Baade PD, Zhang S, Zeng H, Bray F, Jemal A6, $\mathrm{Yu}$ XQ and He J: Cancer statistics in China, 2015. CA Cancer J Clin 66: 115-132, 2016.

3. Graff RE, Meisner A, Ahearn TU, Fiorentino M, Loda M, Giovannucci EL, Mucci LA and Pettersson A: Pre-diagnostic circulating sex hormone levels and risk of prostate cancer by ERG tumour protein expression. Br J Cancer 114: 939-944, 2016.

4. Cornford P, Bellmunt J, Bolla M, Briers E, De Santis M, Gross T, Henry AM, Joniau S, Lam TB, Mason MD, et al: EAU-ESTRO-SIOG guidelines on prostate cancer. Part II: Treatment of relapsing, metastatic and castration-resistant prostate cancer. Eur Urol 71: 630-642, 2017.

5. James ND, de Bono JS, Spears MR, Clarke NW, Mason MD, Dearnaley DP, Ritchie AWS, Amos CL, Gilson C, Jones RJ, et al: Abiraterone for prostate cancer not previously treated with hormone therapy. N Engl J Med 377: 338-351, 2017.

6. Sweeney CJ, Chen YH, Carducci M, Liu G, Jarrard DF, Eisenberger M, Wong YN, Hahn N, Kohli M, Cooney MM, et al Chemohormonal therapy in metastatic hormone-sensitive prostate cancer. N Engl J Med 373: 737-746, 2015.

7. Sammon JD, Abdollah F, Reznor G, Pucheril D, Choueiri TK $\mathrm{Hu}$ JC, Kim SP, Schmid M, Sood A, Sun M, et al: Patterns of declining use and the adverse effect of primary androgen deprivation on all-cause mortality in elderly men with prostate cancer. Eur Urol 68: 32-39, 2015

8. Armitage JO and Sidner RD: Antitumour effect of cimetidine. Lancet 1: 882-883, 1979.

9. Wang WT, Chen YH, Hsu JL, Leu WJ, Yu CC, Chan SH, Ho YF, Hsu LC and Guh JH: Terfenadine induces anti-proliferative and apoptotic activities in human hormone-refractory prostate cancer through histamine receptor-independent Mcl-1 cleavage and Bak up-regulation. Naunyn Schmiedebergs Arch Pharmacol 387: 33-45, 2014

10. Blaya B, Nicolau-Galmés F, Jangi SM, Ortega-Martínez I, Alonso-Tejerina E, Burgos-Bretones J, Pérez-Yarza G, Asumendi A and Boyano MD: Histamine and histamine receptor antagonists in cancer biology. Inflamm Allergy Drug Targets 9: 146-157, 2010.

11. Zheng Y, Xu M, Li X, Jia J, Fan K and Lai G: Cimetidine suppresses lung tumor growth in mice through proapoptosis of myeloid-derived suppressor cells. Mol Immunol 54: 74-83, 2013

12. Tanaka S, Sakaguchi M, Yoneyama H, Usami Y and Harusawa S: Histamine $\mathrm{H} 3$ receptor antagonist OUP-186 attenuates the proliferation of cultured human breast cancer cell lines. Biochem Biophys Res Commun 480: 479-485, 2016.

13. Lin JJ, Zhao TZ, Cai WK, Yang YX, Sun C, Zhang Z, Xu YQ, Chang T and Li ZY: Inhibition of histamine receptor 3 suppresses glioblastoma tumor growth, invasion, and epithelial-to-mesenchymal transition. Oncotarget 6: 17107-17120, 2015.

14. Donoso AO and Banzan AM: H1- and H2-histamine receptor antagonists and induced release of prolactin in male rats. Neuroendocrinology 30: 11-14, 1980.

15. Livak KJ and Schmittgen TD: Analysis of relative gene expression data using real-time quantitative PCR and the 2(-Delta Delta C(T)) method. Methods 25: 402-408, 2001.

16. Lin Y, Fukuchi J, Hiipakka RA, Kokontis JM and Xiang J: Up-regulation of $\mathrm{Bcl}-2$ is required for the progression of prostate cancer cells from an androgen-dependent to an androgen-independent growth stage. Cell Res 17: 531-536, 2007.

17. Liu C, Lou W, Armstrong C, Zhu Y, Evans CP and Gao AC: Niclosamide suppresses cell migration and invasion in enzalutamide resistant prostate cancer cells via Stat3-AR axis inhibition. Prostate 75: 1341-1353, 2015.
18. Barber AG, Castillo-Martin M, Bonal DM, Jia AJ, Rybicki BA, Christiano AM and Cordon-Cardo C: PI3K/AKT pathway regulates E-cadherin and Desmoglein 2 in aggressive prostate cancer. Cancer Med 4: 1258-1271, 2015.

19. Koh CM, Bieberich CJ, Dang CV, Nelson WG, Yegnasubramanian S and De Marzo AM: MYC and prostate cancer. Genes Cancer 1: 617-628, 2010.

20. Gray IC, Stewart LM, Phillips SM, Hamilton JA, Gray NE, Watson GJ, Spurr NK and Snary D: Mutation and expression analysis of the putative prostate tumour-suppressor gene PTEN. Br J Cancer 78: 1296-1300, 1998.

21. Green AJ, Gelfand JM, Cree BA, Bevan C, Boscardin WJ, Mei F, Inman J, Arnow S, Devereux M, Abounasr A, et al: Clemastine fumarate as a remyelinating therapy for multiple sclerosis (ReBUILD): A randomised, controlled, double-blind, crossover trial. Lancet 390: 2481-2489, 2017.

22. Rossing MA, Scholes D, Cushing-Haugen KL and Voigt LF: Cimetidine use and risk of prostate and breast cancer. Cancer Epidemiol Biomarkers Prev 9: 319-323, 2000

23. Ragnarsson O, Johannsson G, Geterud K, Lodding $P$ and Dahlqvist P: Inadequate testosterone suppression after medical and subsequent surgical castration in a patient with prostate cancer. BMJ Case Rep 2013: pii: bcr2013010395, 2013.

24. Wang Q, Li W, Zhang Y, Yuan X, Xu K, Yu J, Chen Z, Beroukhim R, Wang H, Lupien M, et al: Androgen receptor regulates a distinct transcription program in androgen-independent prostate cancer. Cell 138: 245-256, 2009.

25. Yeap BB, Krueger RG and Leedman PJ: Differential posttranscriptional regulation of androgen receptor gene expression by androgen in prostate and breast cancer cells. Endocrinology 140: 3282-3291, 1999.

26. Liu X, Ledet E, Li D, Dotiwala A, Steinberger A, Feibus A, Li J, Qi Y, Silberstein J, Lee B, et al: A whole blood assay for AR-V7 and ARv567es in patients with prostate cancer. J Urol 196: 1758-1763, 2016.

27. Yu Z, Chen S, Sowalsky AG, Voznesensky OS, Mostaghel EA, Nelson PS, Cai C and Balk SP: Rapid induction of androgen receptor splice variants by androgen deprivation in prostate cancer. Clin Cancer Res 20: 1590-1600, 2014.

28. Sharma NL, Massie CE, Ramos-Montoya A, Zecchini V, Scott HE, Lamb AD, MacArthur S, Stark R, Warren AY, Mills IG and Neal DE: The androgen receptor induces a distinct transcriptional program in castration-resistant prostate cancer in man. Cancer Cell 23: 35-47, 2013.

29. Mills IG: Maintaining and reprogramming genomic androgen receptor activity in prostate cancer. Nat Rev Cancer 14: 187-198, 2014.

30. Li Z, Alyamani M, Li J, Rogacki K, Abazeed M, Upadhyay SK, Balk SP, Taplin ME, Auchus RJ and Sharifi N: Redirecting abiraterone metabolism to fine-tune prostate cancer anti-androgen therapy. Nature 533: 547-551, 2016.

31. Pfanzagl B, Mechtcheriakova D, Meshcheryakova A, Aberle SW, Pfragner R and Jensen-Jarolim E: Activation of the ileal neuroendocrine tumor cell line P-STS by acetylcholine is amplified by histamine: Role of H3R and H4R. Sci Rep 7: 1313, 2017.

32. Davenas E, Rouleau A, Morisset S and Arrang JM: Autoregulation of McA-RH7777 hepatoma cell proliferation by histamine H3 receptors. J Pharmacol Exp Ther 326: 406-413, 2008.

33. Medina V,Croci M,Crescenti E, Mohamad N, Sanchez-JiménezF, Massari N, Nuñez M, Cricco G, Martin G, Bergoc R and Rivera E: The role of histamine in human mammary carcinogenesis: $\mathrm{H} 3$ and $\mathrm{H} 4$ receptors as potential therapeutic targets for breast cancer treatment. Cancer Biol Ther 7: 28-35, 2008.

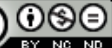

This work is licensed under a Creative Commons Attribution-NonCommercial-NoDerivatives 4.0 International (CC BY-NC-ND 4.0) License. 